\title{
Entre o cristal e a chama: a natureza \\ e o uso do conhecimento científico e dos saberes \\ tradicionais numa disciplina do Curso de Formação \\ Intercultural para Educadores Indígenas \\ da Universidade Federal de Minas Gerais (FIEI/UFMG)
}

\author{
Between the crystal and fire: the nature and use of scientific \\ and traditional knowledge in a discipline of Intercultural \\ Formation Course for Indigenous Teachers of the Federal \\ University of Minas Gerais (FIEI/UFMG)
}

Juarez Melgaço Valadares $^{1}$ • Célio da Silveira Júnior ${ }^{1}$

\begin{abstract}
Resumo: Neste trabalho discutem-se os significados que envolvem a formação intercultural para educadores indígenas a partir das tensões decorrentes do encontro das diferentes culturas e da pluralidade de saberes em sala de aula. As reflexões têm como panorama as questões em torno da função social da educação escolar indígena em suas articulações com as dinâmicas culturais em suas comunidades, considerando-se tanto a construção da educação básica nas aldeias quanto a formação docente na Universidade Federal de Minas Gerais (UFMG). Para tanto, são analisadas algumas situações vivenciadas em sala de aula, em uma disciplina de formação de educadores indígenas, sob a metáfora do texto visto como chama ou cristal. A experiência permitiu uma melhor compreensão da realidade da educação escolar dos povos indígenas como contato cultural, e não como folclore.
\end{abstract}

Palavras-chave: Interculturalidade. Ensino de ciências. Educação escolar indígena. Conhecimento científico.

\begin{abstract}
This paper discusses the meanings that involve cross-cultural training for indigenous educators from the tensions arising from the meeting of different cultures and the plurality of knowledge in the classroom. Reflections have as scenery the issues concerning to the social function of indigenous school education in their links with the cultural dynamics in their communities, considering both the construction of basic education in the villages and teachers training at the Federal University of Minas Gerais in Brazil (UFMG). For this purpose, some situations experienced in the classroom, in a training course for indigenous teachers, under the text metaphor viewed as flame or crystal, are analyzed. This experience has enabled a better understanding of the reality of school education of indigenous peoples as cultural contact, not as folklore.
\end{abstract}

Keywords: Indigenous school education. Science education. Indigenous knowledge. Scientific knowledge.

\footnotetext{
${ }^{1}$ Universidade Federal de Minas Gerais (UFMG), Faculdade de Educação, Belo Horizonte, MG, Brasil. E-mail: <juarezm@ufmg.br>
} 


\section{O mundo que cerca e o mundo sem cercas}

Selvagens! Em consequência dessa resposta, dada por um aluno indígena, o professor desata uma risada que ecoa por toda a sala e, quem sabe, por todo o prédio escolar. Não foi uma risada de deboche. Pelo contrário. A risada refletia a concordância do professor com a reflexão feita pelo estudante. Mas também parecia refletir uma grata surpresa com essa resposta e com as outras que os estudantes davam, e que ele ia registrando no quadro. Enquanto a risada se prolongava, os estudantes olhavam entre si, também surpresos com a situação.

A situação, um pouco incomum, não se relacionava com um comportamento inusitado do professor. Os estudantes já estavam acostumados, há três anos, às suas diferentes aulas. Aulas dialogadas e provocativas, sempre. Aulas em que os mais sisudos esforçam-se para conter seus sorrisos, sem sucesso. Mas nessa aula, algo diferente aconteceu. Por quê?

$\mathrm{Na}$ aula, era desenvolvida a Disciplina Tópicos Especiais, com uma turma de estudantes indígenas da Faculdade de Educação (FaE) da Universidade Federal de Minas Gerais (UFMG). Especificamente, com a turma da habilitação Ciências da Vida e da Natureza (CVN) do Curso de Formação Intercultural para Educadores Indígenas (FIEI), constituída por indígenas das etnias Xakriabá (MG) e Pataxó (BA e MG).

O FIEI é dirigido à população indígena que ainda não teve a oportunidade de se qualificar para a profissão de educador por meio de um curso superior. Além das aulas presenciais, a estrutura curricular do curso exige que parte da graduação aconteça nas próprias comunidades dos estudantes. Assim, o curso está organizado em tempos e espaços diversificados, dando ênfase e valorizando a experiência sociocultural dos educandos, com tempos de formação na UFMG (módulos) e tempos no próprio espaço de atuação e vivência dos estudantes (intermódulos). Tem a duração de quatro anos.

O curso habilita os educadores indígenas para atuarem como professores de ensino fundamental e médio em suas respectivas comunidades, e oferece instrumentos pedagógicos, para que os indígenas possam atuar na escolarização de crianças, jovens e adultos, levando em consideração suas especificidades e seus modos de vida, contribuindo para melhorar a educação em suas comunidades. Tem como objetivo formar e habilitar professores indígenas em licenciatura plena, com enfoque intercultural, nas áreas de concentração em línguas, artes e literaturas; matemática; ciências da vida e da natureza; ciências sociais e humanidades. Outra meta, essencial, é discutir metodologias participativas nos processos de ensino e aprendizagem, em uma perspectiva voltada para a educação intercultural, isto é, uma educação que promova o diálogo entre as culturas, reconhecendo as diferenças e fortalecendo o conhecimento indígena tradicional.

Sobretudo, os textos e as discussões consideram a realidade socioambiental nas aldeias e as interações entre as escolas indígenas e seus sujeitos. Pretende formar educadores interculturais, comprometidos com sua comunidade indígena, e que possam intervir em sua realidade, de modo a transformá-la, tendo como eixo central a reflexão sobre a prática vivida. Tal iniciativa significa colocar em ação um currículo que ostenta uma tensão conceitual entre os saberes locais e os conhecimentos acadêmicos, o que implica em um contato cultural que se caracteriza por: (a) ser desigual, uma vez que as identidades em contato geram relações de poder; (b) ser conflitivo, por colocar em risco a constituição da própria identidade; e (c) ser 
produtivo, pois, após o encontro, as identidades se modificam e se transformam, criando novas identidades. (GUTIERREZ, 2014).

Formar educadores interculturais: que significados têm aqui? É pensar, de saída, que os povos indígenas possuem concepções e visões de mundo próprias. Em seguida, criar experiências educativas a partir das quais eles possam explicitar as suas representações e colocá-las para explicar os mundos físico e social. São, sobretudo, colocadas lado a lado com as explicações científicas. A convivência de representações díspares sobre determinados temas sugere a escola como espaço fronteiriço, como local de intercâmbios recíprocos e construção de identidades.

Duas trajetórias surgem desse contexto inicial: primeiramente, as duas formas de representação convivem lado a lado e o debate reforça cada um dos modelos identitários e as crenças compartilhadas. Um caminho interessante são os racionalismos setoriais propostos por Mortimer (1996) a partir da leitura do perfil epistemológico proposto por Bachelard (1984 apud MORTIMER, 1996, p. 30). Nessa caminhada, o significante e agente questionam o sujeito, desafiando-o a produzir um conhecimento para além do que já possui. Paralelamente ao pulo dado em seu perfil conceitual, o sujeito é motivado a encontrar seus pontos de impasse e a construir sua autonomia. Segundo Villani e Barolli (2006), o agente (professor) deve recalcar o seu saber, colocando-se como puro suporte do movimento do outro (aluno). O efeito é o de um mundo sem cercas: produzir uma abertura para novos saberes a partir de visões de mundo que cada um carrega consigo mesmo. É a possibilidade de respeitar as diferenças e de integrá-las em uma unidade que não as anule (FLEURI, 2003).

A segunda trajetória é marcada pela opção em mostrar que a episteme é superior à doxa (PESSANHA, 1987). Nesse caminho, os conhecimentos científicos devem substituir os saberes tradicionais, bem como suas formas de expressão, uma vez que não há alteridade, e as diferenças são desconsideradas. Tal visão dificultaria o reconhecimento e as interações entre as culturas da escola e da experiência, pois uma seria o prolongamento da outra. O conhecimento científico escolarizado seria como flores cercadas por uma coroa de espinhos: os saberes tradicionais são deixados nos umbrais das portas da sala de aula (MORTIMER, 1998). A ciência como discurso surge acima de qualquer suspeita, como adesão a um ideal absoluto: aquele que pronuncia esse discurso fala de um lugar de que tudo sabe e que não presta contas a ninguém. Espera-se mudar a relação do aluno com o conhecimento científico, e, de certa forma, fazer com que o aluno mantenha um esforço na aprendizagem, porque deve ser assim. Para Villani e Barolli (2006), caso esse discurso consiga fazer laços, estamos diante de um mundo com cercas: estamos frente a um guru que conquista seus seguidores ou de um chefe que se apodera de parte do trabalho de seu liderado.

Não temos dúvidas de que essas duas trajetórias integram as grandes narrativas no campo das teorias educacionais. De modo geral, encontramos atualmente a concepção de que o significado é colado no significante, de que devemos construir sujeitos independentes e autônomos, de que há relações diversas entre cultura, saber e poder, e cujo foco, muitas vezes, silencia as relações de poder que ocultam os temas relacionados aos questionamentos de gênero, raça, etnia, religião e sexualidade. Nesse texto procuramos resgatar aspectos relevantes dessas grandes narrativas, relacionadas à interculturalidade. Enfrentamos, sobretudo, a temática mais ampla dos processos de escolarização em suas relações com os processos culturais (GOMES; MIRANDA, 2014). 


\section{Mestres feiticeiros, homem da boca sagrada, outros bichos e gentes que surgiram na disciplina do FIEI: Quem sou eu?}

Foi em um dos módulos na UFMG que a turma CVN teve o primeiro contato com a disciplina Tópicos Especiais. A intencionalidade no planejamento da disciplina era trazer aos professores, alunos e alunas indígenas certo estranhamento cultural, isto é, formas de pensar e visões de mundo que pudessem fazê-los refletir sobre suas identidades. O grande objetivo era fazê-los perceber outras formas de pensar as identidades culturais, que carregam as marcas da complexidade e das interações culturais já ocorridas. O contato com outros grupos e culturas implicava abrir o olhar ao diferente, ao deslocamento do conhecido para o desconhecido, e que não é só com o outro que interagimos, mas também com o outro que habita em nós, uma vez que existem outras “alteridades” (FLEURI, 2003).

A pergunta Quem sou Eu? inaugurou a aula inicial. Na aula seguinte, ocorreu o encontro com a história do rap e do funk, contada por um rapper, a seguir discutiu-se cibercultura com uma socióloga, e depois foi trabalhado com uma professora de Artes o conceito de performance, de forma a expressar e lidar com suas vivências. Nesse meio tempo, os alunos foram a um Café Sociocientífico, cujo tema foi Astronomia na sala de aula, de onde trouxeram a pergunta: Existe um Conbecimento Verdadeiro?

Na penúltima aula da disciplina, o professor iniciou retomando a questão proposta aos estudantes: Quem sou eu? Registrou as respostas de um estudante e, a partir delas, discorreu sobre a ideia de pertencimento que emergia da questão posta. Falou de família e de como somos elos entre os nossos antepassados e as gerações futuras. Contou a sua história familiar. Discutiu se a inteligência poderia ser transmitida "biologicamente" de pai para filho, uma espécie de dom, ou se essa transmissão seria o resultado do contexto cultural vivenciado pelos sujeitos. Disse que somos seres compósitos, uma vez que somos integrantes de vários grupos sociais e, consequentemente, perpassados por diversos saberes. E, por sermos assim, vivenciamos sempre situações conflitivas, que ocorrem inclusive entre membros de um mesmo grupo social. Exemplificou com a situação dos estudantes ali presentes, que pertencem a vários grupos: grupo dos indígenas, de professores indígenas, de estudantes universitários, de estudantes da UFMG, de estudantes CVN, de membros de associações diversas, de bolsistas PIBID, etc. As provocações do professor, com perguntas e respostas, foram registradas no quadro e em notas de campo.

Em seguida discutiu-se a questão: $O$ que é o conbecimento verdadeiro? Na noite anterior, esses mesmos estudantes e o professor tinham ouvido em um Café Científico que a ciência representaria a busca pelo conhecimento verdadeiro. Então, o que seria esse conhecimento verdadeiro? Que inter-relações poderiam existir entre esse conhecimento verdadeiro e o tradicional indígena? Ou, melhor, o conhecimento tradicional indígena seria o conhecimento verdadeiro? Nessa visão, o saber é fundado nos sentidos, no raciocínio indutivo ("o sol vai nascer amanhã porque sempre nasceu todos os dias"). Constitui um componente de todas as culturas e uma verdade compartilhada por toda uma comunidade ("a lua influencia o corte de cabelo porque cem por cento da comunidade indígena acredita que seja assim”).

O professor fez circular entre os estudantes a chamada "caixa-preta", artefato que continha pequenos objetos que não podiam ser vistos, uma vez que a caixa encontrava-se lacrada. A intenção era apresentar uma discussão sobre o que se constitui como saber objetivo. Numa acepção muito tradicional, esse saber objetivo define a ciência como o conhecimento 
verdadeiro, controlado e produzido por uma comunidade intersubjetiva, e apagado de sua linguagem os valores subjetivos. Cupani (1989, p. 18) debruça-se sobre as questões articuladoras entre teoria e realidade:

Essa correspondência reconhecer-se-ia na validade dita universal das afirmações científicas, ou seja, na sua inevitável aceitação por parte de todos os que têm a devida competência específica (matemática, sociologia, etc). Por sua vez, essa validade universal seria o resultado do proceder metódico, a constante crítica e autocrítica dos cientistas, a atitude imparcial ante os assuntos pesquisados e a prescindência de interesses outros que a busca da verdade.

A partir da manipulação do artefato, os estudantes passaram a elaborar hipóteses sobre o que ele continha. Esse levantamento de hipóteses seria utilizado pelo professor como ponto de partida para a discussão sobre a forma como se dá a construção dos modelos científicos. Disse que a elaboração desses modelos parte sempre da curiosidade, de uma pergunta, mas com o modelo e as hipóteses já presos a uma teoria. Dessa necessidade, uma metodologia é utilizada para se tentar responder à pergunta. Tudo isso, de forma análoga à que os estudantes realizaram em relação à caixa-preta. Testadas as suas hipóteses, podemos construir um modelo satisfatório, ancorado na teoria e na "resistência do objeto a ser conhecido". Em decorrência, a teoria será aceita, até que ela não responda satisfatoriamente a outras hipóteses postas ${ }^{3}$. Então, concluiu que um conhecimento pode ser considerado verdadeiro, mas traz junto a ideia de provisoriedade, além de questionar a noção da imagem da ciência que se aproxima cada vez mais do real.

Mas isso deixava sem resposta a questão principal: o que é o conhecimento verdadeiro? Qual conhecimento deveria ser considerado o verdadeiro, já que, algumas vezes, a "caixa-preta" é "aberta" de forma diferente pela religião, pela ciência, e pelo conhecimento tradicional indígena? Como surgiu o mundo, por exemplo? Discutidas algumas "verdades" sobre essa questão com a turma, um dos estudantes perguntou: por que há várias verdades? Por que ela não pode ser única? Essas respostas não viriam ainda nesse momento. Finda essa etapa da aula, os estudantes retornariam para a leitura de um texto sobre os rituais corporais de um povo, os Nacirema (MINNER, 1956).

O texto foi escolhido por se tratar de outra visão cultural relativa aos brancos (não índios). A intenção é refletir a respeito dos significados que se apresentaram no encontro das culturas propiciadas por essa situação de interculturalidade. O texto tratava dos estranhos rituais do povo Nacirema em relação aos seus corpos, dos seus costumes exóticos, e de sua obsessão pela magia. Terminada a leitura silenciosa pelos estudantes, o professor quis saber suas impressões sobre o texto. Surgiram as respostas sobre o povo descrito no texto que provocaram a já referida e contagiante gargalhada do professor. Dentre elas ${ }^{4}$ :

\footnotetext{
${ }^{3}$ Não há dúvidas de que a atividade da "caixa-preta" simplifica em muito o processo da produção de conhecimentos científicos. Além disso, há o risco de levar os alunos a uma versão de cunho empirista.

${ }^{4}$ As respostas citadas, apesar de aqui agrupadas, foram dadas por alunos diferentes.
} 
Selvagens! Agressivos! Violentos! Apostam tudo no conbecimento tradicional deles, acima de qualquer suspeita! Muita fé nos curandeiros! São guiados pelo medo! Relações baseadas na retribuição por presentes!

Registradas as respostas dos estudantes no quadro, o professor discorreu sobre essas sociedades que, embora com comportamentos tão estranhos, viviam sob uma determinada lógica. Procurava-se, a partir do texto, criar um distanciamento reflexivo que levasse os alunos a perceberem as várias culturas presentes no texto dos Nacirema e que envolviam a todos. No caso específico dos Nacirema, tão exóticos, cujos hábitos provocaram tanto o estranhamento dos estudantes indígenas, esse povo era constituído por nós (brancos, etnocêntricos), o que não ficava explícito no texto. Daí a reação que o professor teve em relação às respostas dos estudantes. Esses, por sua vez, ao ouvirem a "revelação" de quem seriam os Nacirema, ficaram estupefatos, ao perceberem quem eram esses sujeitos tão "primitivos". Foi o momento de o professor concluir a aula, dizendo que, se deixarem, é o conhecimento do povo Nacirema que quer se tornar a única verdade: uma visão cientificista da ciência e da sociedade. De forma semelhante, a "caixa-preta" requer um distanciamento reflexivo, a fim de perceber visões diferenciadas, envolvidas na produção do conhecimento científico na discussão sobre a atividade em sala. É nesse sentido que pensamos uma educação intercultural, porque

[...] neste contexto, a educação passa a ser entendida como o processo construído pela relação tensa e intensa entre diferentes sujeitos, criando contextos interativos que, justamente por se conectar dinamicamente com os variados contextos culturais em relação aos quais os diferentes sujeitos desenvolvem suas respectivas identidades, torna-se um ambiente criativo e propriamente formativo. (FLEURI, 2003, p. 31)

No que tange aos processos escolares, o conhecimento científico torna-se obstáculo para a entrada de outros discursos em sala, o que de fato implica que não interessa a ninguém termos uma única verdade, e nem que haveria pessoas autorizadas a falar sobre um conhecimento verdadeiro, e pessoas desautorizadas a isso.

\section{Descobridores dos sete mares: as nossas contingências e os aprendizes de mestres historiadores}

As atividades desenvolvidas levaram cada um de nós a pensar se vivemos realmente em um tempo marcado pela noção de diferença e pluralidade. Na Antiguidade, pluralidade sempre foi uma manifestação da doxa, sendo responsabilidade do racionalismo clássico integrar essas múltiplas realidades por uma unidade soberana, cujo resultado final seria a mudança da doxa pela unidade da ciência, pela episteme. Para Pessanha (1987, p. 61), "[...] fora desse território de necessário consenso de todos os espíritos aclarados pela ciência única, ficaria o sombrio reino das impressões instáveis e inconsistentes, das ideias falsas e obscuras".

Pensar a educação indígena é participar dessa discussão entre o pensamento verdadeiro e as ideias e culturas consideradas falsas nesse campo. Os povos indígenas carregam com eles uma tensão entre conhecimento científico e saberes tradicionais, manifesta entre o poder da 
cultura oral como forma de transmissão de conhecimento - bem como do pensamento humanista centrado na palavra - e a predominância de um pensamento apoiado no cálculo e rigor matemático, e cada vez mais levado à rejeição da palavra e do sujeito.

Interrogamos, como objeto de pesquisa, o que ocorre quando essa experiência de contato com uma cultura diversa questiona a cada um de nós na continuidade de nós mesmos, na organização de nossas identificações, na coerência entre as nossas formas de pensar e atuar, e na eficácia dos códigos comuns a todos aqueles que pertencem a um conjunto. (KAËS, 2014). Encontramos a dimensão do negativo e da alteridade como mecanismo de promoção da identidade social e das culturas diversas.

Assim, nossa investigação se deu a partir da perspectiva e experiência dos alunos e alunas indígenas em sala de aula, bem como da impossibilidade de desprezar as experiências e valores daquele grupo. Poderíamos, também, considerar apenas as estruturas subjacentes que moldariam a experiência educacional do aluno e do professor, independentemente de quem eles sejam e da história particular de cada um.

A nossa investigação, sobretudo, pauta-se pelo estranhamento produzido a partir da leitura do texto dos Nacirema. Esse é o ponto básico que procuramos adiantar nesse trabalho: o que marcou cada um desses alunos após essa aula? O que abalou ou reforçou em suas certezas? Que reflexões fazem de suas respostas ao texto? Que releituras fizeram após a revelação sobre quem seriam os sujeitos Nacirema? Existe um conhecimento verdadeiro, afinal? Quem pode falar sobre ele? Tais questões podem estar respondidas nos textos que os estudantes elaborariam com base em suas impressões sobre a aula, a pedido do professor. Esperemos ansiosos por essas impressões, sempre na forma de narrativas.

\section{Intérpretes em busca de sentidos}

A noção de que os Nacirema acreditam piamente em seus feiticeiros e curandeiros sugere um conhecimento daquilo que Kaës (2014) denomina posição ideológica das alianças mantidas entre os membros de seu grupo, quando mantêm as identificações e as certezas elementares requeridas para alimentar a coesão do grupo e seu pensamento coletivo. Mas quais os motivos de palavras como violência, agressividade e repressão para expressar essa sociedade? Talvez porque toda aliança para manter a coesão do grupo mostre, também, mesmo sem palavras, os critérios que definem quem deva ser excluído. Fica evidenciado que os alunos perceberam tais exclusões a partir da leitura do texto. Educar as crianças nessa estrutura a eles perceptiveis seria introduzi-las num mundo cuja essência é o conhecimento único e soberano, e nos rituais estranhos de passagem. Compreender o texto dessa forma é vê-lo como cristal.

Ver esse texto como cristal implica buscar a sua estrutura subjacente. Ao optar pelo significado inerente, admitimos também certo autoritarismo do texto: uma adesão dos Nacirema a um conhecimento tradicional suposto, acima de qualquer suspeita. Mas, se por um lado, esse conhecimento é único e verdadeiro; por outro, dominá-lo não é tão simples: na leitura dos alunos indígenas, as crianças desse povo são formadas dentro das ações repressivas daquele grupo. O conhecimento tradicional é transmitido de forma autoritária às crianças daquele povo, as quais, por sua vez, são obrigadas a aprenderem aquele conhecimento e o terem como acima de qualquer suspeita. A aluna Lu escreveu: 
No comę̧o da leitura achei esse texto muito estranho, não só eu como os colegas da turma, não sabiam de onde vinham e de onde surgiu, e os meninos deram algumas opiniões sobre eles que tratava de um povo selvagem, agressivo, curandeiros, violentos, etc.5.

Segundo Mortimer (1998), lidamos de forma tão automática com a interação entre a linguagem científica escolar e a linguagem cotidiana do aluno, que nos esquecemos de que qualquer fato científico só adquire significado se reconstruído pelo discurso científico escolar. Desvaloriza-se qualquer outra forma de conhecimento que possa existir e explicar o mesmo fenômeno. Vejamos o texto de outra aluna:

R: Esse texto retrata bem um povo que é obcecado por mágicas e rituais agressivos, onde os curandeiros incentivam o ritual, e assim o conhecimento tradicional está acima de qualquer suspeita. Onde quem passava pelos rituais eram obrigados a dar presentes, $e$ as crianças eram 'aculturadas' ou seja, eram obrigadas a aprender e passar por tudo que se dizia rituais.

Nessa hora, diversos alunos mencionam que preferem "ter como rito de passagem arrancar os dentes de peixes e riscarem diversas partes do corpo até sangrar do que compartilhar os rituais corporais daquele povo estranho", visão também compartilhada por outro indígena:

Ed: Podemos anotar alguns pontos sobre o texto: o conhecimento tradicional acima de qualquer suspeita, a selvageria e a agressividade daquele povo, $e$ as crianças serão aculturadas dessa mesma maneira. Enfim, adorei a aula de hoje.

Façamos nossa a pergunta feita por Mortimer (1998, p. 99) sobre a linguagem científica escolar, que funciona como ritos de passagem de nossos alunos: "Estará essa linguagem, aparentemente neutra, que constrói um mundo asséptico, atemporal e sem sujeitos, contribuindo para construir novos universos para todos cidadãos ou, ao contrário, para perpetuar as relações de poder em nossa sociedade?”

Ficam claros o estranhamento e as dificuldades que a linguagem científica traz para os alunos e alunas, uma vez que os sujeitos desaparecem nos textos, descontextualizando os processos de aculturação. Porém, a noção do texto como chama, cuja discussão inicial instaura um processo instável de construção de sentido, passará a ser defendida por esse mesmo aluno, quando o professor menciona que aquele povo, os Nacirema, é o não índio, o branco. Aquele povo não é prolongamento do eu, do nós indígena para os alunos do curso. Assim, a reviravolta ocorre na percepção de que aquele conhecimento acima de qualquer suspeita consiste no conhecimento científico escolarizado; e os outros conhecimentos e saberes, a serem esquecidos, são os saberes tradicionais indígenas. Podemos pensar no texto como chama, levando a uma proliferação de sentidos, ou seja, todo sentido é possível, dependente da pessoa que o constrói. Escreve o aluno A:

\footnotetext{
${ }^{5}$ Todos os excertos foram retirados das narrativas dos alunos e alunas. Estas atividades foram realizadas após cada aula da disciplina.
} 
A outra parte que achei muito interessante é se existe conbecimento verdadeiro. $O$ conbecimento verdadeiro existe mas de acordo com o pensamento de cada um, ou seja, a bipótese que cada um cria para definir um fato. E também o que me chamou muita a atenção foram algumas frases do texto, como por exemplo: o homem da boca sagrada. Fiquei me perguntando o porquê desse homem da boca sagrada.

O aluno cai em um relativismo? Ou nos indica o efêmero, o mutável, o plural, e, por que não, nos fala do dilacerado (“E fiquei me perguntando o porquê desse homem da boca sagrada?"). Tanto Bellei (1986) quanto Mortimer (1998) sugerem-nos que nem toda interpretação é possível. Por outro lado, o caráter provisório do conhecimento científico, dado como várias verdades, é percebido pelo leitor I, quando escreve:

Foi levantada a pergunta, em uma aula anterior, se a verdade existe (se o conbecimento verdadeiro existe?). Pelo que entendi, todo cientista quer demonstrar que a sua ciência é que é verdadeira, só existe uma verdade. Mas existem outros cientistas que, pela curiosidade, querem saber se há outra verdade por trás dessa verdade que o cientista nos coloca diante da ciência.

Não há dúvidas de que as marcas de uma ciência clássica, universal, atemporal e ahistórica aparecem na linguagem científica; e as suas marcas não foram construídas de uma vez só, mas estabelecidas ao longo do desenvolvimento da ciência (MORTIMER, 1998). Podemos pensar na leitura desse texto como cristal ou como chama. Como cristal, a ideia de conhecimento acima de qualquer suspeita, único, e que se impõe geracionalmente às crianças Nacirema foi percebido por todos os alunos indígenas. Como chama, a noção de estranhamento que ele trouxe permitiu que os alunos relativizassem seus conhecimentos, bem como situassem o conhecimento científico e os saberes tradicionais em patamares próximos. Porém, a leitura como chama só foi possível na discussão em sala, em que todos/as foram colocando suas questões sob a orientação do professor. Vejamos o que escreveu o aluno El:

Analiso essa aula como uma teoria do conhecimento, pois pude observar que a ciência, por mais que busca compreender [as coisas] nunca chega a uma teoria verdadeira, pois está sempre despertando a inteligência e a curiosidade no homem. [...] Assim a ciência nunca tem uma medida exata, está sempre em busca de novas teorias. E sobre a leitura do texto não sei se compreendi tudo que estava falando ... mostrava uma visão estranha por que eles achavam que o conhecimento deles é mais forte do que outros dependentemente da cultura.

No excerto anterior, notamos uma visão da natureza do conhecimento científico de cunho ainda próximo ao empirismo (As verdades estão aí, basta descobri-las), e percebemos a aluna considerar o texto como uma obra cristalizada (BELLEI, 1986). Nesse caso, o cientista procura ler o mundo em sua estrutura imanente, em seu desejo único de controlá-lo, em busca de novas teorias, de forma a poder sonhar com a verdade final. Sobre esse estruturalismo, temos BELLEI (1986) que afirma que ao cientista, mais do que ao professor, persegue o desejo de cristalização total do texto e da captura da sua literalidade essencial. $\mathrm{O}$ excerto a seguir, de $\mathrm{Ch}$, permite ver que o texto como chama aproxima o aluno de sua cultura: 
Com isso aprendi a maneira de como nós vivemos numa sociedade, onde as pessoas buscam a suas verdades, uma forma de viver própria, foi uma aula riquíssima, de como perceber a forma de vivência do povo que está ao nosso redor.

O reforço da cultura e das identificações entre os povos indígenas reforçam tanto o compartilhamento dos ideais quanto provoca o reconhecimento do não nós, isto é, da alteridade. Visto como chama, o texto e o observador estabelecem uma relação de intersubjetividade, reconhecendo o potencial do contexto e as concepções prévias dos sujeitos leitores. As interações muitas vezes ocorrem em termos passionais, de proximidade, e não em forma de neutralidade. Porém, o texto como cristal é uma das possibilidades em compreendê-lo como chama.

\section{As nossas palavras como pesquisadores}

Nossas reflexões tiveram como pano de fundo as questões em torno da função social da educação escolar indígena em suas articulações com as dinâmicas culturais em suas comunidades. Essa discussão foi concomitante à tensão entre os conhecimentos acadêmicos e os conhecimentos tradicionais indígenas. Mostramos que a cultura indígena está na escola quando o aluno indígena está presente, mas correndo o risco de passar despercebida, em função do predomínio de uma concepção cientificista do conhecimento. (COHN, 2014).

Mortimer (1998) traz as seguintes características da linguagem científica: aparente neutralidade e a presença de uma voz. universal. Epistemologicamente, essas duas características fornecem a sustentação do trabalho docente em sua forma tradicional. $\mathrm{Na}$ sua visão, uma das dificuldades para o ensino de ciências é o pouco diálogo entre a linguagem científica e a linguagem cotidiana, e entre a teoria científica e a prática dos fenômenos. Para o autor, essa situação resulta numa

[...] ausência de fenômenos que possam mostrar a natureza das construções teóricas e dos modelos científicos como construções matemáticas e discursivas para interpretação e descrição de uma realidade muito mais complexa, tudo isso torna a ciência escolar algo desinteressante e sem sentido para a grande maioria dos estudantes. (MORTIMER, 1998, p. 114)

O autor ainda completa que, dessa concepção de mundo e do ensino a ela associada, perpetuamos as relações de poder em nossa sociedade, excluindo aqueles que não se encaixam em nosso universo discursivo. O que poderia ter de gratificante em ver o texto como cristal? Do ponto de vista organizacional, o aluno pode pensar que, aderindo a essa concepção, e seguindo-a a risca, efetivamente garante a sua aprendizagem. Talvez, por isso mesmo, uma verdade única é melhor do que várias verdades, em função das concepções didático-pedagógicas. Sendo o conhecimento científico único e universal, o professor utiliza para resolver qualquer conflito, o que fornece a esse profissional enorme satisfação. Além disso, os conhecimentos do aluno não são necessários, uma vez que esses sujeitos não possuem valor frente àqueles que o professor determinou como soberanos em qualquer situação (VILLANI; BAROLLI, 2006). Ou, então, o conhecimento tradicional indígena é mero trampolim para se chegar ao conhecimento científi- 
co. No que se refere à educação indígena, a tensão entre saberes tradicionais e conhecimentos científicos acompanham todo o curso. Outra tensão também se manifesta nesse encontro entre as duas culturas: a oral e a escrita. Nesse caso, propiciar atividades que resgatem a oralidade torna-se importante para as trocas recíprocas.

Uma das saídas indicadas por este trabalho é ver o texto como chama, uma vez que gera possibilidade de mais de uma interpretação das ideias, resultando na convivência de visões complementares ou conflitivas, reforçando e permitindo o refinamento de cada uma delas. Como chama, a nossa leitura propicia situações dialógicas, uma vez que o sujeito é convocado, em vez de ser eliminado ou passivizado. Tal fato sugere que o professor, mesmo partindo do conhecimento científico, questione seu aluno para que produza algo além de seus conhecimentos prévios, o que até então lhe satisfazia. O produto será um saber relacionado ao conhecimento científico, reforçando as crenças do aluno. Em formas mais radicais, o fato de que o professor não indique caminhos para os alunos pode parecer uma "falta de controle na aprendizagem do outro": o professor fornece sugestões, mas a decisão final é do aprendiz. Nesse sentido, o discurso de que o professor é um assessor não é tão simples, mesmo que consideremos que a autonomia do aluno esteja se ampliando cada vez mais.

Fleuri, apoiando-se nas ideias de Homi Bhabha (1998 apud FLEURI, 2003, p. 22), traz para a cena a possibilidade de ir além de certa rigidez que perpassa o termo "pluralidade cultural", de forma a fazer-nos pensar no hibridismo que surge nos entrelugares e entreolhares dos diferentes sujeitos e grupos socioculturais, sem que as suas identidades sejam anuladas, porque

[...] é sob esta perspectiva que a educação intercultural se preocupa com as relações entre os seres humanos culturalmente diferentes uns dos outros. Não apenas na busca de apreender o caráter de várias culturas, mas sobretudo na busca de compreender os sentidos que suas ações assumem no contexto de seus respectivos padrões culturais e na disponibilidade de se deixar interpelar pelos sentidos de tais ações e pelos significados constituídos por tais contextos. (FLEURI, 2003, p. 31)

A vivência dessa experiência trouxe novas reflexões em relação à nossa prática. A pedagogia intercultural supõe sempre a aparição do conflito (GASCHÉ, 2010; GONZALO; ORTEGA, 1998), isto é, formula-se uma pedagogia cujo ponto inicial é os conflitos culturais e para os quais são necessárias ações que transbordam os muros da escola na tentativa de resolvê-los. Esses conflitos podem ocorrer tanto em posicionamentos sobre situações sociais vivenciadas concretamente pelos grupos em contato, quanto em questões conceituais de determinada área de conhecimento em contexto de sala de aula. São esses conflitos vividos de forma construtiva? Esses conflitos propiciam uma mudança na forma de compreender o conhecimento científico e os saberes tradicionais? A narrativa da professora indígena $S$ responde a essas dúvidas:

Aprendi a ver a escola com outro olhar. Valorizar, entender, debater e também dar opiniões. Ajudou também no fortalecimento da nossa cultura, como na música, na dança e na pintura corporal. Ajudou também a fazer as comparações da escola não-indígena com a indígena. Hoje na nossa escola temos mais autonomia de decidir o que é bom para a escola e a comunidade em geral. 
Além disso, um currículo cujas disciplinas se tornam espaços para a ação social, política e cultural referenda a construção de uma prática investigativa e de pesquisa da realidade dos povos indígenas e de suas escolas, bem como a construção didática da memória pessoal, do grupo e do território. Mais do que oferecer um arsenal de leituras críticas do contexto, a pesquisa como metodologia de ensino traz consequências para a prática docente: a indissociação método-conteúdo. (DELIZOICOV; ANGOTTI; PERNAMBUCO, 2002).

Nesse caso, a pesquisa, como trajetória individual ou coletiva, é possibilidade de construções curriculares inovadoras, pois gera a possibilidade de respeito e tolerância pela cultura do outro; o que ensinar e o que aprender surgem dessas interações entre os diversos discursos que ocorrem em determinado espaço e tempo. Assim, capturar esses discursos é função de professores indígenas nas escolas das aldeias. Perguntamos: nossas ações e atividades têm permitido um olhar e uma melhor compreensão da realidade dos povos indígenas e, consequentemente, reforçado as suas formas de ver e ler o mundo? Nessa leitura, o texto como chama torna-se um "sentido suspenso" a ser atualizado por leitores diversos (BELLEI, 1986).

Segundo Bellei (1986), se é possível pensar que qualquer leitura de um texto depende sempre de uma opção inicial de lê-lo como cristal ou como chama, é preciso também lembrar que cada uma dessas opções teóricas, quando colocada em prática, revela-se insuficiente diante do vigor do texto. Deixa ele sempre um resto que persiste e incomoda, e que não se submete nem à estratégia da chama, nem a do cristal.

\section{Referências}

BELLEI, S. L. P. O cristal em chamas: uma introdução à leitura do texto literário. Florianópolis: Editora da UFSC, 1986.

COHN, C. A cultura nas escolas indígenas. In: CUNHA, M. C.; CESARINO, P. N. (Org.). Políticas culturais e povos indígenas. São Paulo: Cultura Acadêmica, 2014. p. 313-338.

CUPANI, A. O. A objetividade científica como problema filosófico. Caderno Brasileiro de Ensino de Física, Florianópolis, v. 6, p. 18-29, jun. 1989. Número especial. Disponível em: $<$ https://periodicos.ufsc.br/index.php/fisica/article/view/10067/14908>. Acesso em: 17 fev. 2016.

DELIZOICOV, D.; ANGOTTI, J. P.; PERNAMBUCO, M. M. Ensino de ciências: fundamentos e métodos. São Paulo: Cortez, 2002. (Coleção Docência em formação).

FLEURI, R. M. Intercultura e educação. Revista Brasileira de Educação, Rio de Janeiro, n. 23, p. 16-35, maio/ago. 2003.

GASCHÉ, J. ¿Qué son ‘saberes' o ‘conocimientos’ indígenas, y qué hay que entender por 'diálogo’? In: PÉREZ, C.; ECHEVERRI, J. A. (Ed.). Memorias 1er Encuentro Amazónico de Experiencias de Diálogo de Saberes, Leticia, 2008. Leticia: Editorial Universidad Nacional de Colombia, 2010. 
GOMES, A. M. R.; MIRANDA, S. A. A formação de professores indígenas na UFMG e os dilemas das culturas Xakriabá e Pataxó. In: CUNHA, M. C.; CESARINO, P. N. (Org.). Políticas culturais e povos indígenas. São Paulo: Cultura Acadêmica, 2014. p. 455-483. GONZALO, L. A. A.; ORTEGA, P. S. De la tolerancia a la interculturalidade: un proceso educativo em torno a la diferencia. Madrid: Anaya, 1998.

GUTIERREZ, A. L. G. Notas conceituais sobre a relação entre justiça curricular e currículo intercultural. In: LOPES, A. C.; ALBA, A. (Org.). Diálogos curriculares entre Brasil e México. Rio de Janeiro: EdUERJ, 2014.

KAËS, R. As alianças inconscientes. São Paulo: Ideias \& Letras, 2014.

MINNER, H. O ritual do corpo entre os Nacirema. American Anthropologist, Arlington, v. 58, p. 503-507, 1956. Tradução de: Body ritual among the Nacirema. Disponível em: $<$ https://comunicacaoeesporte.files.wordpress.com/2011/03/nacirema.pdf $>$. Acesso em: 1 fev. 2016.

MORTIMER, E. F. Construtivismo, mudança conceitual e ensino de ciências: para onde vamos? Investigações em Ensino de Ciências, Porto Alegre, v. 1, n. 1, p. 20-39, 1996. Disponível em: <http://www.if.ufrgs.br/ienci/artigos/Artigo_ID8/v1_n1_a2.pdf>. Acesso em: 1 fev. 2016.

Sobre chamas e cristais: a linguagem cotidiana, a linguagem científica e o ensino de ciências. In: CHASSOT, A. (Org). Ciência, ética e cultura na educação. São Leopoldo: Editora Unisinos, 1998. p. 99-118.

PESSANHA, J. A. M. Cultura como ruptura. In: BORNHEIM, G. A. et al. Cultura brasileira: tradição contradição. Rio de Janeiro: J. Zahar: FUNARTE, 1987. p. 59-90.

VILLANI, A.; BAROLLI, E. Os discursos do professor e o ensino de ciências. ProPosições, Campinas, v. 17, n. 1, p. 155-175, jan./abr. 2006. Disponível em: <http://www. proposicoes.fe.unicamp.br/proposicoes/textos/49_dossie_villania_etal.pdf $>$. Acesso em: 1 fev. 2016. 